\title{
Beyond Normal Competencies: Understanding Organisational Designs to Develop and Sustain IT-Related Capabilities
}

\author{
Acklesh Prasad \\ Queensland University of Technology \\ acklesh.prasad@qut.edu.au \\ Peter Green \\ University of Queensland \\ p.green@business.uq.edu.au \\ Jon Heales \\ University of Queensland \\ j.heales@business.uq.edu.au
}

\begin{abstract}
Information technology (IT) is an important resource in organisations. Organisations leverage their IT resources with their IT-related capabilities to achieve, and sustain their competitive position. However, IT resources are dynamic, and evolve continually. Furthermore, competitive pressures and turbulent economic conditions mean that organisations continually invest in these dynamic IT resources. These situations mean that organisations need to sustain their IT-related competencies to leverage opportunities offered by the new IT resources. Research about ways to develop new, and sustain existing, IT-related capabilities is limited. A possible reason for the lack of research in this area is the lack of validated measurement items of theoretical constructs necessary to investigate ways to create new, and sustain, existing, IT-related competencies and capabilities. In this study, we suggest an environment in which organisations could build new, and sustain their existing IT-related capabilities. We report on the resources and processes that establish this environment. We also report on the development of valid measures of the elements of this environment. Analysis of pilot test data revealed that the measurement items purport to measure what they intended to measure. This study's outcome is useful in extending our understanding of IT-related competence development to secure sustainable IT-related business value from the IT resources.
\end{abstract}

Keywords: Business value, sustainable IT-related capabilities, resource-based view, dynamic capabilities, instrument development

\section{INTRODUCTION}

This study suggests how organisations could develop new, and sustain their existing, IT-related capabilities. IT-related capabilities are competences that leverage organisations' IT resources. This study is important because competitive pressures and forces compel organisations to make continuous investment in IT resources. However, organisations will need to identify ways to leverage these resources differently (Powell and Dent-Micallef, 1997). This situation is because IT resources are readily available, and any commodity-related advantage would quickly erode upon its acquisition by 
competitors. As a result, organisations continually face the challenge of finding ways to leverage unique business value from their IT resources.

Our review of the extant literature highlights that various suggestions are provided on the impetus for continued investment in IT resources. There is also ample research that suggests organisations' ITrelated capabilities that leverage the IT resources obtain competitive advantage (see for example, Jeffers, Muhamma and Nault, 2008; Melville, Kraemer and Gurbaxani, 2004; Oh, Ng and Teo, 2007). These IT-related capabilities include top management commitment, shared organisational knowledge, and an agile and flexible IT infrastructure (Wade and Hulland, 2004). IT resources develop continually. That is, these resources will continually present new opportunities to organisations to strengthen their competitive position. This situation, and the existence of a turbulent business environment, (Pavlou and El Sawy, 2006) mean that organisations need to find ways to continuously develop new, and update their existing, competencies to sustain their IT-related competitive advantage. Research to extend knowledge to leverage the IT resources by developing and sustaining these capabilities is limited.

We present an environment, which is a unique combination of various resources on which competencies could be developed and maintained. We also present a detailed description of the process of establishing reliable measures of the elements of this environment. We adopt a resourcecentric view, the dynamic capabilities framework (Teece, 2007), and suggest that organisations need to organise their resources internally and identify the synergies between these resources. The synergies between these resources create a higher-level resource. A higher-level resource (environment) is the outcome of combination of appropriate levels of related resources, and its value to organisations is more than the sum of the value of the individual resources. This higher-level resource is dynamic because it would have the capacity to reorganise itself through the ability to absorb and incorporate environmental changes. This situation means that the potential of this higherlevel resource to drive competitive advantage for an organisation is greater than the sum of the individual resources (Grant, 2008). This environment is important because the evolving nature of the IT resources requires continuous development of competencies. Organisations can develop new, and sustain their existing, IT-related capabilities on this dynamic higher-level resource.

We suggest four common (lower-level) resources needed to establish this higher-level organisational resource (i.e., the dynamic IT-deployment environment). These resources include a decentralised organisational design relating to task allocation, which accords more authority to users to interact with the business processes (Bresnahan, Brynjolfsson and Hitt, 2002; Brynjolfsson and Hitt, 1998), and an organisational design that promotes teamwork (Bresnahan et al., 2002; Brynjolfsson and Hitt, 1998). It also includes a congruent incentive system where the workers compensations align to the work design structures (Osterman, 1994), and a lateral IT governance structure that has representation of the various levels of management (Doll and Torkzadeh, 1987; Karimi, Bhattacherjee, Gupta and Somers, 2000; Prasad, Green and Heales, 2012; Prasad, Heales and Green, 2010).

In this paper, we describe how these four resources synergise to form the dynamic IT-deployment environment. We then discuss the development of the measurement items for these resources. This exercise is important because future research on sustaining IT-related competencies is contingent upon robust measurement items for suggested factors. The suggested lower-level factors have been subject to research in various disciplines, and some form of measures for these factors already exist. The competence development research, however, is a new setting with different target contacts and organisations. This situation warrants a thorough consideration on development of reliable measures for the constructs. Developing and validating reliable measurement instruments for theoretical concepts is important if we want to obtain appropriate empirical evidence to test our theories. 
In information systems (IS) research, a number of instruments that consider exploratory concepts of underlying theories lack reliability and validity (Moore and Benbasat, 1991; Straub, 1989). Proper validation of measurement items is an important phase in IS empirical research. We developed a pool of measures for the factors, and our extensive validation process resulted in five measures of organisation design related to task allocation, three measures for organisation design related to teamwork, five measures for incentive system, and seven measures for lateral IT governance structure. A field-based pilot test and subsequent assessment of the measurement properties of pilot test data showed that measures display normal properties and tend to measure what they intended to measure. This outcome presents a tool that could help organisations develop new, and sustain existing, IT-related capabilities. It also paves the way to investigate avenues for sustaining various ITrelated capabilities within this environment.

The rest of this paper progresses as follows. The next section introduces the main concepts of dynamic capabilities theory, and explains how the four suggested resources co-create a dynamic capability of a dynamic IT-deployment environment. Following this section, we provide a detailed discussion on the procedure used to develop the measurement items of the components of this environment. This work includes a discussion on the confirmatory field study and associated statistical analysis used to establish the validity and reliability of the measures. The paper concludes with a discussion of key issues, summary of the contributions, limitations, and directions for future research.

\section{THEORETICAL FRAMEWORK}

The resource-centric perspective (Barney, 1991; Mata, Fuerst and Barney, 1995; Teece, 2007; Teece, Pisano and Shuen, 1997) views an organisation as a product of various resources. The resourcecentric perspective suggests that some organisational resources are common across organisations, while others are heterogeneous (Barney, 1991; Mata et al., 1995; Wade and Hulland, 2004). The resource-centric perspective asserts that organisations could leverage their heterogeneous resources to attain and sustain their competitive position. This situation is because organisations are able to achieve different and (better) outputs with their heterogeneous resources. In relation to IT resources, they are termed the IT-related capabilities. One resource-centric perspective, the resource-based view (RBV), suggests various IT-related capabilities for organisations. This perspective suggests that organisations need to have these IT-related capabilities to achieve superior IT-driven performance. However, the RBV does not suggest ways to sustain these IT-related capabilities. Sustainable ITrelated capabilities are renewed competencies that leverage homogenous IT resources. Sustainable ITrelated capabilities have become important in today's environment where organisations have dynamic IT resources at their disposal.

Organisations require continuous reorganisation of their resources to leverage opportunities and manage threats (Coase, 1937; Milgrom and Roberts, 1990; Teece, 2007). Initial, ad-hoc, reorganisations (Barua, Kriebel and Mukhopadhyay, 1995; Barua, Lee and Whinston, 1996; Edgeworth, 1881; Milgrom, Roberts and March, 1995) will not provide a dynamic and sustainable new environment. This situation is because such organisation is basic, and it would be easily imitated by other organisations. Organisations would be able to develop and sustain competencies through dynamic and deeper-level reorganisation of their resources. That is, organisations need to move away from reorganisation as an activity pattern (Milgrom and Roberts, 1990) to a more systematic reorganisation of resources.

The dynamic capabilities framework (Teece, 2007; Teece et al., 1997) suggests a systematic and coordinated reorganisation of organisational resources upon which organisations can build and sustain 
their key competencies. The dynamic capabilities perspective asserts that common organisational factors on their own cannot increment the IT-related capabilities. However, a tactical reorganisation of organisational resources can co-create higher-level dynamic resources that can help organisations sustain their IT-related capabilities. In fact, these higher-level resources themselves could be organisations' unique competencies. These higher-level resources would be dynamic because they are difficult-to-imitate combinations of organisational, functional and technological skills (Teece, 2007). Organisations could use this foundation to build, maintain and enhance their distinctive and difficult to imitate advantages (Teece et al., 1997).

Organisations will be able to achieve these higher-level resources through their innovative responses. These responses include appropriately adapting, integrating, and reconfiguring internal and external organisational skills, resources, and functional competencies (Teece et al., 1997). Organisations' past choices influence domains of competence, and at any given time, they must follow a certain trajectory of competence development (Teece et al., 1997). Further, the dynamic capability perspective suggests that organisations can organise better certain types of economic activities internally (Coase, 1937). Competencies and capabilities resulting from organising and getting things done internally is the key component in sustaining performance advantages (Coase, 1937). This outcome is possible because internal organisation takes place in a more multilateral fashion, with patterns of behaviour and learning orchestrated in a much more decentralised fashion (Teece et al., 1997). Processes, paths, and positions are factors that can help determine a firm's distinctive competence and dynamic capabilities. These competencies and capabilities embed in organisational processes of one kind or another. The shared innovative changes between these processes explain the essence of organisations' dynamic capabilities and competitive advantage (Teece et al., 1997). We adopt these theoretical perspectives to suggest four factors, and the synergy of these factors would form a higher-level resource, the dynamic IT-deployment environment. We discuss these factors in the next section and suggest how the synergy between them creates the higher-level resource of a dynamic IT-deployment environment.

\section{DEVELOPMENT OF A DYNAMIC IT-DEPLOYMENT ENVIRONMENT}

In this section, we discuss how four resources - a decentralised organisational design relating to task allocation, a decentralised organisational design relating to teamwork, a congruent incentive system, and a lateral IT governance structure - form a dynamic IT-deployment environment. Such environments are essential in ensuring organisations' ability to renew their IT-related competencies to leverage their IT resources.

\section{A Lateral IT Governance Structure}

In this subsection, we discuss how a lateral IT governance structure in the form of an IT steering committee contributes to the development of a dynamic IT-deployment environment. The lateral concept in this structure relates to its agility, and its ability to recognise synergy in the knowledge of different levels of management. IT Governance, at an abstract level, is a subset discipline of Corporate Governance, and focuses on ways to manage information and IT assets (Weill and Ross, 2004). IT governance frameworks and structures specify the decision rights and accountability frameworks to encourage effective management of IT resources (Weill and Ross, 2004). IT governance includes foundational mechanisms in the form of leadership, and organisational structures and processes that ensure organisations' IT objectives align to their strategic objectives (IT Governance Institute, 2007). This required alignment means that the governance of IT resources embraces planning, organising, and controlling of IT activities. The IT governance structures have shown to serve various IT-related purposes in organisations (see for example, Brown, 1997; Xue, Liang and Boulton, 2008). These structures are categorised as centralised, decentralised, or federal 
(Sambamurthy and Zmud, 1999); or business monarchy, IT monarchy, Feudal, IT duopoly, and anarchy (Weill and Ross, 2004). These structures facilitate the establishment of critical functions for making IT decisions. The most prominent of these functions is a lateral IT governance structure, mainly in the form of an IT steering committee (Karimi et al., 2000; Van Grembergen, De Haes and Guldentops, 2004).

A lateral IT governance structure embraces operational, tactical, and strategic IT and business unit management (Karimi et al., 2000). The key role of this structure is the setting of policies and organisation-wide coordination of IT resources (Karimi et al., 2000). The committee is entrusted with the task of linking IT strategy with business strategy by setting the strategic direction, matching corporate concerns with technological potential, and building commitment to policies (IT Governance Institute, 2007; Nolan, 1982). Chaired by a top executive, the committee meets periodically to discuss IT direction, approve and rank projects, review performance, formulate or approve technology policies, determine resource levels, and recommend major initiatives (Earl, 1993). A successful IT governance vehicle requires communication amongst all parties based on constructive relationships (Bowen, Chung and Rohde, 2007; Johnson and Lederer, 2005). This aspect is an essential characteristic in the constitution of this IT governance structure. This structure is a key vehicle to understanding organisations' current IT-related competencies, and forge ways to increment these competencies.

\section{A Decentralised Organisation Design related to Task Allocation}

In this subsection, we discuss how a decentralised organisational design relating to allocation of tasks contributes to the development of a dynamic IT-deployment environment. The concept of organisational design relates to decision-making and authority establishing mechanisms in particular organisational settings. The human resources are one of organisations' key resources. Effective human resource management (HRM) practices can develop new organisational competencies and differentiate them from their competitors (Huselid, 1995). While human resources are easily tradable, an effective and agile human resource cohort is difficult to mimic. This situation is because effective HRM systems are ones that simultaneously exploit the potential for complementarities and synergies among the HRM practices (Becker and Gerhart, 1996; Huselid, 1995).

Organisations' human resources can provide significant business value at business process and firm levels. This outcome is possible because the human resources facilitate the fit of various resources, including the IT resources, to the business processes. This means human resources provide unique capabilities to organisations. Good HRM practices would ensure that these competencies are sustained (Wright and McMahan, 1992). Thus, the extent to which an organisation can sustain its HRM-related advantages is contingent upon how it capitalises on its value-generating human resources.

However, organisations frequently do not leverage the maximum value from their human resources. This situation is because employees often perform below their maximum potential (Baily, 1993). Organisational efforts to elicit discretionary effort from employees can provide returns in excess of any relevant costs (Baily, 1993). Good human resources practices would influence employee skills and motivation. Such practices include presence of organisational structures and designs that provide employees with the ability to control how they perform their roles (Baily, 1993). This situation best relates to a decentralised organisation design. Organisational designs that involve the specification of decision rights, performance evaluation systems, and compensation systems, can help in achieving better outcomes from employees (Brickly, Smith and Zimmerman, 1996; Hitt and Brynjolfsson, 1997; Jensen and Meckling, 1992). 
Organisations possess and use many different types of information. People, however, have a finite ability to process and communicate this information (Hitt and Brynjolfsson, 1997). When communication is costly and centralised, and decision makers have an infinite capacity to digest information, a centralized organisational structure will economize on communication costs (Hitt and Brynjolfsson, 1997). Such a structure, however, places a heavy burden on central decision makers. Further, knowledge can be general or specific (Hayek, 1945). Specific knowledge is difficult to convey, and it is more costly to transfer (Jensen and Meckling, 1992). This situation arises because the specific feature of knowledge is that individuals know more than they can state (Polanyi, 1962; Polanyi, 1966). As people have limited capacity to process information, highly specific information is likely to reside at the lower levels of organisation (Hitt and Brynjolfsson, 1997). To take advantage of this specific knowledge, decision rights should be collated with necessary knowledge (Jensen and Meckling, 1992). An organisational structure, where actors with specific knowledge have decision rights, will ensure appropriate leverage and wider communication of that unique specific knowledge. This outcome is analogous to a decentralised organisational structure.

A decentralised organisational structure puts the knowledge and the people together. Performance is broadly associated with a work system that includes a decentralised decision making authority (Brynjolfsson and Hitt, 1997). The contribution of a highly motivated workforce will be limited if jobs are structured, or programmed in such a way that employees do not have the opportunity to use their skills to refine the way they perform their tasks (Baily, 1993). This design is relevant in today's IT-intensive organisational setting, and is an important catalyst in forming a dynamic IT-deployment environment.

\section{A Team-Work Based Decentralised Organisational Design}

In this subsection, we discuss how a decentralised organisational design relating to teamwork contributes to the development of a dynamic IT-deployment environment. The concept of teamwork relates to organisations' human resources ability to share their knowledge and understanding in performing various set tasks. Today's IT-backed collaborative tools like the social network platforms, and shared IT infrastructures, provide an ideal opportunity for organisations' human resources to work efficiently in teams. Collaborative IT tools facilitate a move away from traditional hierarchy towards an open organisation, and promotes a team-based structure (Powell, Lovallo and Caringal, 2006). IT tools such as e-mail, social media, and conferencing facilitate coordination within and across business units. A decentralised organisational design that ties decision rights and knowledge together would promote an environment that encourages employees to interact and adopt a teambased approach. As work-based technologies become more common, organisational performance becomes increasingly affected by organisations' capacity to manage the team-based approach (Nolan and Croson, 1995). HRM practices that encourage participation amongst employees, and allow them to improve how they perform their work, can also contribute to sustained performance (Huselid, 1995). Such HRM initiatives include cross-functional teams, job rotation, and quality circles (Huselid, 1995).

The task allocation and the teamwork aspects of a decentralised organisational design are critical to ensure a better fit of an organisation's processes and their human resources. These aspects provide human resources with greater autonomy with their task, and a greater freedom to manage the fit of the technology to their managed business processes. Thus, a decentralised organisational structure nurtures an environment that allows participation amongst employees to improve on how they perform their tasks. The aspects of a decentralised organisational design for task allocation, and an environment that promotes sharing of skills and knowledge are human resource related organisational design issues capable of establishing a dynamic IT-deployment environment on which organisations could develop new or better their IT-related competencies. 


\section{A Congruent Incentive System}

In this subsection, we discuss how a congruent incentive system contributes to the development of a dynamic IT-deployment environment. An incentive system is a structure to reward performance and motivate employees on individual and/or group levels. A decentralised organisational design that embraces localised task allocation and promotes teamwork encourages better a use of operational level knowledge in organisations. However, such a system can also exacerbate agency problems (Jensen and Meckling, 1992). In the absence of appropriate incentive systems, workers do not necessarily use their decision-making authority in the best interest of the organisation (Hitt and Brynjolfsson, 1997). Appropriate incentive systems align workers goals to those of the organisation. Workers seek appropriate compensation for their willingness to share knowledge. Effective sharing and leveraging of specific knowledge is only possible when an organisation appropriately rewards the efforts of its employees.

Systematic changes and considerations in work practices are important for improving the work environment, and subsequently, organisations' productivity (Ichniowski, Shaw and Prennushi, 1997). That is, organisations work policies should be part of a coherent incentive system and not developed in isolation (Baker, Gibbons and Murphy, 2002; Holmstrom, 1999; Kandel and Lazear, 1992; Milgrom and Roberts, 1990; Milgrom et al., 1995). Incentive systems based on objective performance measures can increase the effectiveness of related policies, including a shared work environment (Baker et al., 2002). Teamwork will also make group-based incentives more effective when firms provide workers with greater autonomy (Kandel and Lazear, 1992). Team environments are more effective when organisations adopt a set of complementary practices, including employment security, flexible job assignments, skills training, and communication procedures (Milgrom et al., 1995).

\section{The Development of the Dynamic IT-Deployment Environment}

In this subsection, we discuss how the above four factors and resources combine through their synergy to develop a dynamic IT-deployment environment. There is synergy between organisational design relating to task allocation and teamwork and reward systems. The resultant environment of this synergy is appropriate to engage in effective decision-making relating to the adoption and use of the IT resources. The fourth component, a lateral IT governance structure, which adopts and sets directions for use of IT resources, is an ideal vehicle that transmits the knowledge on the fit of IT resources and IT-related know to the decision makers. The suggested dynamic IT-deployment environment recognises the importance of the users of technology from the outset, and attempts to present an environment where they would feel motivated to apply and share their knowledge to fit the acquired IT resources to the business processes. In this environment, there will be recursive learning and sharing of ideas and thoughts. The product of these recursions will be a rich pool of IT-related specific knowledge. The suggested lateral IT governance structure will communicate this rich specific IT-related knowledge to the decision makers. The IT deployment benefits and challenges experienced at the IT-deployment level is made known at the decision making level.

Operational-level managements are custodians of information on IT deployment benefits and challenges experienced at the IT-deployment level. This situation arises because they represent the workforce. This specific information filters up to the top-level decision-makers when the operational level managers become part of the lateral IT governance structure. Sharing of this information through the lateral IT governance structure of the IT steering committee will improve the decisionmakers understanding on the use of the IT resources by the organisation. The resultant decisionmaking will accommodate the concerns of the workforce at the operational level of IT resource consumption. This achievement would mean that the workforce would be motivated and they would demand more value from their IT resources. The result of this coordination has a dual purpose, and it is recursive. First, the decision makers will have the current information set to use and make IT- 
related decisions that are most important for their an organisation at that point in time. Second, such IT-related decisions result in the workforce having access to IT resources that are most relevant for the effective and efficient operation of the business processes. The recursive process of learning and sharing of information within this dynamic IT-deployment environment is a unique dynamic capability on which organisations could continue to make unique use of their acquired IT resources. Figure 1 conceptualises the development of a dynamic IT-deployment environment.

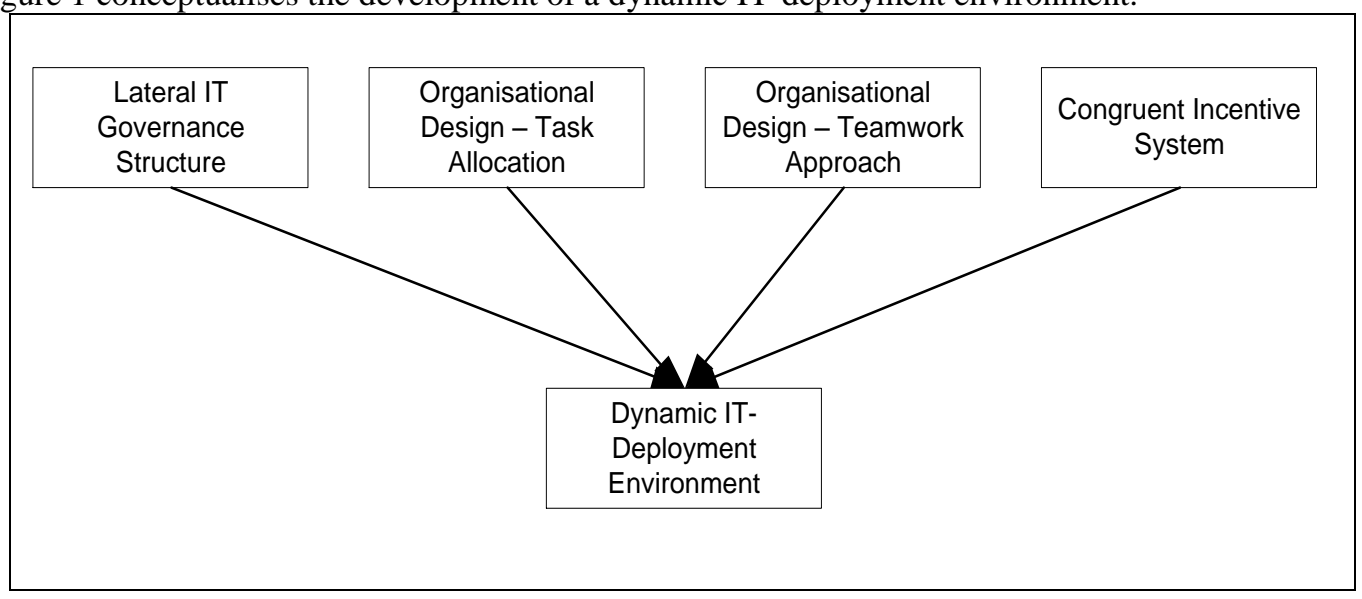

Figure 1. Conceptualisation of the IT-Deployment Platform

\section{INSTRUMENT DEVELOPMENT APPROACH}

The rest of this paper discusses our approach to developing and validating a set of measurement items for the components of the dynamic IT-deployment environment. Figure 2 describes the various stages of this process, which incorporates and extends the methodological procedures first described by Davies (1989) and Moore and Benbasat (1991). Davies (1989) and Moore and Benbasat (1991) present detailed descriptions on instrument validation, which include measurement item creation, measurement item identification, final measurement item selection and refinement using judges and experts, and a field test. This process of instrument development ensures that the measurement items are robust, yet general enough for application in various research environments.

\section{Step 1: Item Creation}

The dynamic capability perspective presents sound specifications on development of a higher-level dynamic capability of a dynamic IT-deployment environment. This study considers the perceptual measures of the organisational resources and factors that form the dynamic IT-deployment environment. As the first step, sets of potential measurement items for the constructs form a pool of candidate items. This process is necessary to ensure content validity (Moore and Benbasat, 1991). Examination of the business value and organisation studies literature, and consultation with industry partners and the academics led to the generation of a pool of candidate items. Ten items per construct can achieve reliability levels of at least 0.80 (Davis, 1989). Table 1 details the candidate measurement items, which are statements to which the respondents indicate their degree of agreement/disagreement on a Likert scale. 


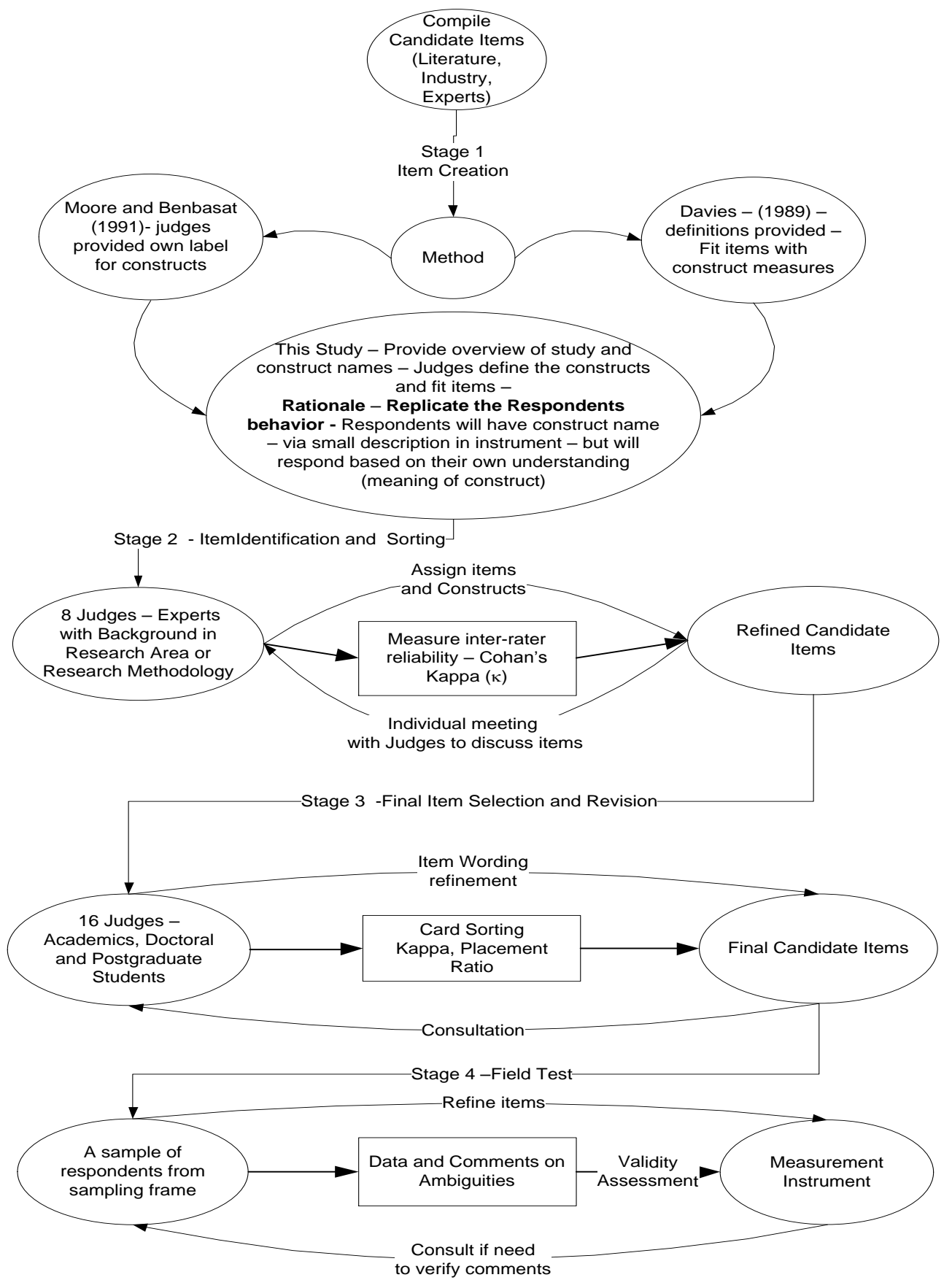

Figure 2. Instrument Development Stages 


\begin{tabular}{|c|c|}
\hline \multicolumn{2}{|c|}{ Lateral IT Governance Structure } \\
\hline IG1 & $\begin{array}{l}\text { We have an IT governance structure that considers steering IT activities that are in line with the } \\
\text { strategic direction of the organisation. }\end{array}$ \\
\hline IG2 & We have an IT governance structure that has greater control of the technology than IT specialists do. \\
\hline IG3 & $\begin{array}{l}\text { We have an IT governance structure that makes resource allocation decisions in the areas of system } \\
\text { development and/or recruitment for the IT function. }\end{array}$ \\
\hline IG4 & The IT steering committee increases visibility and/or for revamping of IT. \\
\hline IG5 & $\begin{array}{l}\text { We have an IT governance structure that considers keeping and sustaining necessary reserved servers } \\
\text { centrally. }\end{array}$ \\
\hline IG6 & We have an IT governance structure that considers IT coordinating requirements and practices. \\
\hline IG7 & We have an IT governance structure that solicits the support of top management for IT activities. \\
\hline IG8 & We have an IT governance structure that recognizes the contribution of operational-level managers. \\
\hline IG9 & We have an IT governance structure that relates well to other IT governance structures. \\
\hline IG10 & $\begin{array}{l}\text { We have an IT governance structure that regularly evaluates its performance with the strategic } \\
\text { objectives of the organisation }\end{array}$ \\
\hline \multicolumn{2}{|c|}{ Organisational Design - Task Allocation } \\
\hline OT1 & The operational level management sets the pace of work. \\
\hline OT2 & The operational level management schedules production work. \\
\hline OT3 & The operational level management distributes this work among the workers. \\
\hline OT4 & The operational level management decides how to accomplish the tasks. \\
\hline OT5 & The operational level management deals with difficult situations in production. \\
\hline OT6 & The operational level management deals with customers in routine situations. \\
\hline OT7 & The operational level management deals with customers over problems or complaints. \\
\hline OT8 & The operational level management reschedules task. \\
\hline OT9 & The operational level management approves ad hoc tasks \\
\hline OT10 & The operational level management plans for future operations \\
\hline \multicolumn{2}{|c|}{ Organisational Design - Teamwork Environment } \\
\hline OE1 & Our business units use self-managing teams effectively. \\
\hline OE2 & Our business units use employee involvement groups effectively. \\
\hline OE4 & Our business units use team building or group cohesion techniques effectively. \\
\hline OE5 & Our organisation promotes teamwork. \\
\hline OE6 & Our organisation promotes shared learning. \\
\hline OE7 & Our organisation holds regular team-building retreats. \\
\hline OE8 & Our organisation rotates work effectively \\
\hline OE9 & Our organisation holds regular social gatherings. \\
\hline OE10 & Our organisation promotes a consultative environment. \\
\hline \multicolumn{2}{|c|}{ Congruent Reward System } \\
\hline IC1 & Our organisation has an equitable incentive based reward system. \\
\hline IC2 & Our organisation provides group incentives. \\
\hline IC3 & Our organisation has performance-based promotion. \\
\hline IC4 & Our organisation performs regular performance reviews. \\
\hline IC5 & Our organisation weights performance aspects effectively. \\
\hline IC6 & Our organisation conducts consultative performance reviews. \\
\hline IC7 & Our organisation conducts regular reviews of its incentive systems. \\
\hline IC8 & Our organisation promotes accelerated performance-based promotion. \\
\hline IC9 & Our organisation effectively links subordinate performances. \\
\hline IC10 & Our organisation adopts a consultative approach in determining incentives \\
\hline
\end{tabular}

Table 1. Construct Measurement Items 


\section{Stage 2: Item Identification and Sorting}

The goal of this stage of measurement item development was to establish initial differences in content validity between the measurement items. Eight recognised IS academics (Judges) with expertise in organisation-related research assessed the correspondence between the pool of candidate items and the intended constructs. The judges performed this task using a validation document with candidate items (in no particular order) on the left side, and the constructs on the right side. This approach adopted a mix of steps from Davies (1989), and Moore and Benbasat (1991). Davies (1989) provided construct definitions and then asked the judges to rank the number of items in relation to their fit with construct definitions. The judges then sorted the items in the construct categories. Moore and Benbasat (1991) did not advise the judges of the underlying constructs. The judges provided their own labels for the constructs. In this study, we provided an overview of the study and the judges were to decide on the definition of the constructs in the relevant context of this study. The judges then related the measures to their defined constructs. This approach, while providing an initial set of categories (constructs), left it to the judges to assign a meaning to the construct and choose measures that best match the meaning. This approach depicts the situation that the potential respondents would encounter when completing the research instrument.

The conciseness of the research instrument means respondents have to rely on the brief descriptions to relate the measures to the context of the study. This stage of the instrument validation process depicts this environment. The judges placed tick(s) under the construct(s) to which they felt the measurement item best related. Interviews with the judges upon the evaluation of the validation document allowed them to discuss any potential conflicts and issues they had with the measures. The interviews were informal, aimed at obtaining detailed feedback on various aspects of the validation document. Table 2 presents the overall percentage correspondence between the measurement items and the constructs by the judges. Table 3 presents the percentage of correspondence between each item and the constructs. Each judge corresponded more than $70 \%$ of the items with the constructs. Judges individual item correspondence to constructs ranged from $25 \%$ to $100 \%$.

\begin{tabular}{|l|l|}
\hline Judge & Percentage Agreement \\
\hline 1 & $70.69 \%$ \\
\hline 2 & $87.93 \%$ \\
\hline 3 & $79.31 \%$ \\
\hline 4 & $79.31 \%$ \\
\hline 5 & $93.10 \%$ \\
\hline 6 & $81.03 \%$ \\
\hline 7 & $84.48 \%$ \\
\hline 8 & $86.21 \%$ \\
\hline
\end{tabular}

Table 2. Overall Percentage Correspondence by Judges

These generic percentage calculations do not provide much information on the nature of agreement between the judges on the relationship between the candidate measurement items and the constructs. Cohen's Kappa ( $\kappa)$ (Cohen, 1960) for each pair of judges estimates their inter-rater reliability. The Kappa is a more robust measure than simple percentage agreement calculations because it accounts for the agreement occurring by chance (Cohen, 1960). The Cohen's Kappa measures the agreement between two raters, who each classify $\mathrm{N}$ items ( 40 in this study) into $\mathrm{C}$ ( 4 in this study) mutually exclusive categories. Table 4 provides the kappa $(\kappa)$ scores for the pairs of judges. The kappa scores indicate that the inter-rater reliability for all except one pair of judges are within the full agreement 
range $(\kappa=0.60-0.80)$ or within the almost perfect agreement $(\kappa=0.81-1.00)$. The excepted pair has a kappa of 0.570 (moderate agreement). The judges' correspondence evaluation responses and the outcome of their interviews formed the basis for selecting (eliminating) candidate items for the constructs. We exercised special care to ensure the remaining pool of items was representative of the constructs.

\begin{tabular}{|l|l|l|l|l|l|l|l|}
\hline Item & $\%$ & Item & $\%$ & Item & $\%$ & Item & $\%$ \\
\hline 1 & 100 & 11 & 87.5 & 21 & 75 & 31 & 100 \\
\hline 2 & 100 & 12 & 100 & 22 & 100 & 32 & 100 \\
\hline 3 & 50 & 13 & 100 & 23 & 100 & 33 & 62.5 \\
\hline 4 & 62.5 & 14 & 75 & 24 & 87.5 & 34 & 62.5 \\
\hline 5 & 87.5 & 15 & 75 & 25 & 87 & 35 & 37.5 \\
\hline 6 & 37.5 & 16 & 87.5 & 26 & 25 & 36 & 100 \\
\hline 7 & 100 & 17 & 87.5 & 27 & 62.5 & 37 & 87.5 \\
\hline 8 & 100 & 18 & 100 & 28 & 87.5 & 38 & 25 \\
\hline 9 & 87.50 & 19 & 100 & 29 & 87.5 & 39 & 25 \\
\hline 10 & 75 & 20 & 87.5 & 30 & 87.5 & 40 & 37.5 \\
\hline
\end{tabular}

Table 3. Percentage Matching by Item (in no particular order)

\begin{tabular}{|l|l|l|l|l|l|l|l|l|}
\hline Judge (J) & J 1 & J 2 & J 3 & J 4 & J 5 & J 6 & J 7 & J 8 \\
\hline J 1 & 1 & & & & & & & \\
\hline J 2 & $0.611^{*}$ & & & & & & & \\
\hline J 3 & $0.570^{*}$ & $0.725^{*}$ & & & & & & \\
\hline J 4 & $0.707^{*}$ & $0.726^{*}$ & $0.764^{*}$ & & & & & \\
\hline J 5 & $0.672^{*}$ & $0.768^{*}$ & $0.768^{*}$ & $0.730^{*}$ & & & & \\
\hline J 6 & $0.613^{*}$ & $0.768^{*}$ & $0.728^{*}$ & $0.670^{*}$ & $0.731^{*}$ & & & \\
\hline J 7 & $0.666^{*}$ & $0.762^{*}$ & $0.820^{*}$ & $0.821^{*}$ & $0.786^{*}$ & $0.746^{*}$ & & \\
\hline J 8 & $0.629 *$ & $0.785^{*}$ & $0.744^{*}$ & $0.705^{*}$ & $0.768^{*}$ & $0.729^{*}$ & $0.801 *$ & 1 \\
\hline
\end{tabular}

Table 4. Kappa ( $\kappa)$ for the Pair of Judges $(* \mathrm{p}<0.001)$

\section{Stage 3: Final Item Selection and Revision}

The purpose of this stage of the instrument development process was to revise the reduced set of candidate items to a final set of measurement items. Moore and Benbasat (1991) and Davies (1989) suggest an index-card sorting test as an appropriate procedure for this step. Sixteen judges, including academics, and doctoral and postgraduate students participated in this process. The judges had varying levels of understanding on IT business value research and organisation studies to depict the pool of potential respondents in a normal field survey environment. Each index card contained a candidate item, and the judges sorted these cards into categories. Consecutively, four groups of judges of four members each performed this sorting exercise, with two groups knowing the categories in which the items are to be sorted (Moore and Benbasat, 1991). This situation meant that in two rounds the judges independently made up categories for the items. The judges also provided a 'degree of fit' in the rounds with the categories provided. Item revisions at the end of each round ensured improved 
reliability at the end to achieve an acceptable Kappa level of 0.70 (Straub, Rai and Klein, 2004). Table 5 presents Kappa scores of each round and placement ratio summary (Moore and Benbasat, 1991).

The results vary between the 'construct' and 'no construct' rounds. The Kappa in both groups improved from the first to the second round. A Kappa of 0.87 at the end of the fourth round indicated that the Judges achieved almost perfect agreement (Cohen, 1960). It is advisable to end the sorting process after reaching Kappa in this range (Straub, Boudreau and Gefen, 2004). Inspection and refinement of the measurement items at the end of each round resulted in better placement ratios and improvement in pairs of Judges' agreements. Table 6 presents the final list of measurement items for the constructs.

\begin{tabular}{|c|c|c|c|c|}
\hline & $\begin{array}{l}\text { Round } 1 \\
\text { (No } \\
\text { Construct) }\end{array}$ & $\begin{array}{l}\text { Round } 2 \\
\text { (Construct) }\end{array}$ & $\begin{array}{l}\text { Round } 3 \\
\text { (No } \\
\text { Construct) }\end{array}$ & $\begin{array}{l}\text { Round } 4 \\
\text { (Construct) }\end{array}$ \\
\hline \multicolumn{5}{|l|}{ Placement Ratio Outcome } \\
\hline Lateral IT Governance Structure & $80 \%$ & $100 \%$ & $89 \%$ & $100 \%$ \\
\hline $\begin{array}{l}\text { Organisation Design - Task } \\
\text { Allocation }\end{array}$ & $55 \%$ & $91 \%$ & $63 \%$ & $96 \%$ \\
\hline $\begin{array}{l}\text { Organisation Design - } \\
\text { Teamwork }\end{array}$ & $46 \%$ & $80 \%$ & $58 \%$ & $88 \%$ \\
\hline Congruent Reward Systems & $59 \%$ & $81 \%$ & $68 \%$ & $89 \%$ \\
\hline \multicolumn{5}{|l|}{ Kappa Analysis } \\
\hline $\begin{array}{l}\text { Average Kappa between pairs of } \\
\text { Judges }\end{array}$ & 0.51 & 0.76 & 0.59 & 0.87 \\
\hline
\end{tabular}

Table 5. Results of Index Card Sorting

The final stage of the instrument testing process involved the conduct of the field test. However, it was necessary to construct a sampling frame before the conduct of the field test. This process was necessary because a field test should involve a sample of potential respondents who would participate in future studies that may adopt these measures. This precaution will also indirectly ensure that the measurement constructs achieve wider applicability. We obtained details from the ORBIS database to develop an appropriate sampling frame. ORBIS is a global database, developed by Bureau van Dijk Electronic Publishing (BvDEP). We obtained the contact details of all Australian private and public companies. We considered the inter-company relationships to ensure that only a copy of the test instrument is send to the target contacts. The final list in the sampling frame consisted of 2493 potential respondents.

\section{Stage 4: Field Test}

Up until this stage, the instrument development process ensured selection of good candidate measurement items. The field test of the instrument ensures that the items measure what they intend to measure. The field test effectively seeks industry validation of the research instrument. Invitations were sent to 2493 contacts to participate in the field test. The sample for the field test included a diverse range of companies representing the major industries and sectors of economy. Data collection for the field test was through survey research. The field test used both mail and online surveys. For the online survey, we sent an email to the target contacts that contained a link to the survey URL. The administration of the field test was consistent with the guidelines suggested by Dillman (2007). The 
administration process included initial delivery of the instrument package to potential respondents and two follow-ups. At the end of the final follow up, progressively, the field test survey secured two hundred and sixty eight (268) valid responses, giving a response rate of $10.75 \%$.

We tested for the non-response bias with the first and the last thirty responses for all measures. The last thirty responses are a proxy for the non-respondents as their responses were received after one of two reminders. This test did not find any significant differences on any of the variables. We also tested for bias associated with mail and online responses and there were no significant differences. There were no issues of missing data.

\begin{tabular}{|c|c|}
\hline \multicolumn{2}{|c|}{ Lateral IT Governance Structure (IT Steering Committee) } \\
\hline ITG1 & $\begin{array}{l}\text { In our organisation, we have an IT governance structure that makes IT-related } \\
\text { resource allocation decisions relating to system development and recruitment, and } \\
\text { training. }\end{array}$ \\
\hline ITG2 & $\begin{array}{l}\text { In our organisation, we have an IT governance structure that improves visibility of IT } \\
\text { and revamps the IT practices. }\end{array}$ \\
\hline ITG3 & $\begin{array}{l}\text { In our organisation, we have an IT governance structure that considers keeping and } \\
\text { sustaining necessary reserved servers centrally. }\end{array}$ \\
\hline ITG4 & $\begin{array}{l}\text { In our organisation, we have an IT governance structure that helps to facilitate the IT } \\
\text { coordinating requirements and practices. }\end{array}$ \\
\hline ITG5 & $\begin{array}{l}\text { In our organisation, we have an IT governance structure that solicits the support of top } \\
\text { management for IT activities. }\end{array}$ \\
\hline ITG6 & $\begin{array}{l}\text { In our organisation, we have an IT governance structure that recognizes the } \\
\text { contribution of operational-level managers. }\end{array}$ \\
\hline ITG7 & $\begin{array}{l}\text { In our organisation, we have an IT governance structure that relates well to other IT } \\
\text { governance structures. }\end{array}$ \\
\hline \multicolumn{2}{|c|}{ Organisation Design - Task Allocation } \\
\hline OTM1 & $\begin{array}{l}\text { In our organisation, the operational level management sets the pace of work of their } \\
\text { subordinates. }\end{array}$ \\
\hline OTM2 & In our organisation, the operational level management schedules work. \\
\hline OTM3 & $\begin{array}{l}\text { In our organisation, the operational level management distributes work among the } \\
\text { subordinates. }\end{array}$ \\
\hline OTM4 & $\begin{array}{l}\text { In our organisation, the operational level management decides how to accomplish the } \\
\text { tasks. }\end{array}$ \\
\hline OTM5 & $\begin{array}{l}\text { In our organisation, the operational level management deals with difficult situations in } \\
\text { production. }\end{array}$ \\
\hline \multicolumn{2}{|c|}{ Organisation Design - Teamwork } \\
\hline OTW1 & In our organisation, the business units use self-managing teams effectively. \\
\hline OTW2 & In our organisation, the business units use employee involvement groups effectively. \\
\hline OTW3 & $\begin{array}{l}\text { In our organisation, the business units use team-building or group cohesion techniques } \\
\text { effectively. }\end{array}$ \\
\hline \multicolumn{2}{|c|}{ Congruent Reward Systems } \\
\hline CRS1 & Our organisation has an equitable incentive based reward system. \\
\hline CRS2 & Our organisation provides group incentives. \\
\hline CRS3 & Our organisation has performance-based promotion. \\
\hline CRS4 & Our organisation performs regular performance reviews. \\
\hline CRS5 & Our organisation weights performance aspects effectively. \\
\hline
\end{tabular}

Table 6. Final IT-Deployment Platform Instrument 
The first step of evaluating the measurement properties of field test data was to conduct an exploratory factor analysis (EFA). The EFA helps evaluate the initial construct validity and reliability. This evaluation provides some indication of the possible misinterpretations of the measurement items. The EFA examines the dimensions of the loading of the scale items to the measured constructs without imposing any clustering constraints or theoretical basis for clustering. The item correlations provide an initial indication of the association between the construct measurements. An evaluation of the correlations between the measurement items revealed that the correlations were mostly significant. This result meant the data satisfied prerequisites of the exploratory factor analysis. We used the statistical tool, SPSS to conduct the EFA. Table 7 (a) and (b) present the correlation matrix and the p-values of the measurement items.

\begin{tabular}{|l|l|l|l|l|}
\hline Items & 1 & 2 & 3 & 4 \\
\hline ITG1 & 0.89 & 0.14 & 0.02 & 0.03 \\
\hline ITG2 & 0.84 & 0.10 & 0.05 & 0.09 \\
\hline ITG3 & 0.83 & 0.05 & 0.05 & 0.04 \\
\hline ITG4 & 0.84 & 0.04 & 0.14 & 0.02 \\
\hline ITG5 & 0.87 & 0.02 & 0.15 & 0.13 \\
\hline ITG6 & 0.83 & 0.18 & 0.02 & 0.08 \\
\hline ITG7 & 0.94 & 0.08 & 0.25 & 0.04 \\
\hline OTM1 & 0.27 & 0.67 & 0.27 & 0.25 \\
\hline OTM2 & 0.14 & 0.87 & 0.29 & 0.02 \\
\hline OTM3 & 0.21 & 0.91 & 0.25 & 0.10 \\
\hline OTM4 & 0.07 & 0.86 & 0.37 & 0.07 \\
\hline OTM5 & 0.31 & 0.84 & 0.25 & 0.16 \\
\hline OTW1 & 0.28 & 0.39 & 0.67 & 0.17 \\
\hline OTW2 & 0.06 & 0.25 & 0.68 & 0.33 \\
\hline OTW3 & 0.02 & 0.32 & 0.77 & 0.30 \\
\hline CRS1 & 0.06 & 0.12 & 0.08 & 0.84 \\
\hline CRS2 & 0.22 & 0.06 & 0.04 & 0.91 \\
\hline CRS3 & 0.05 & 0.14 & 0.35 & 0.68 \\
\hline CRS4 & 0.22 & 0.22 & 0.02 & 0.90 \\
\hline CRS5 & 0.15 & 0.02 & 0.10 & 0.91 \\
\hline & & & & \\
\hline
\end{tabular}

Table 8. EFA Results 


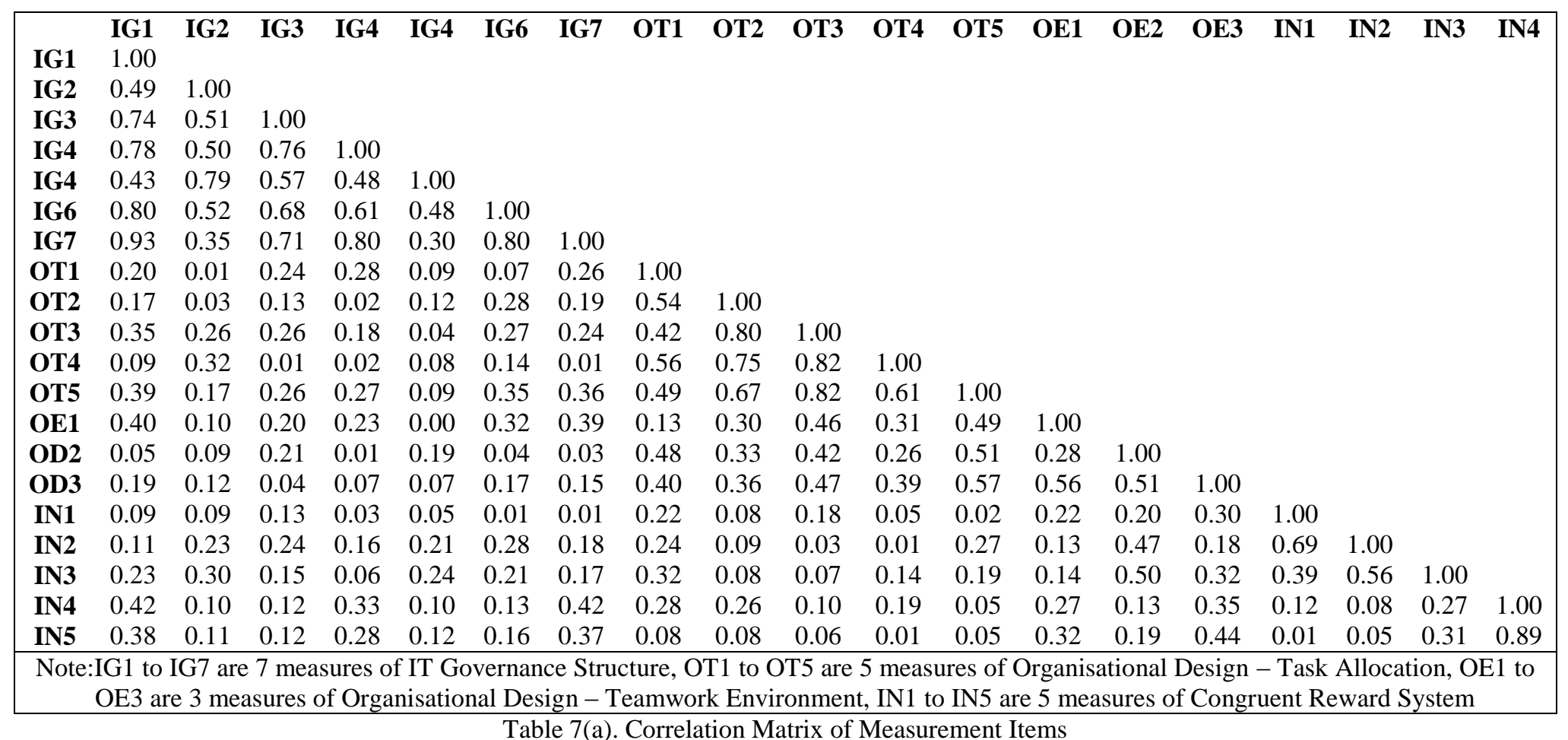

Table 7(a). Correlation Matrix of Measurement Items 


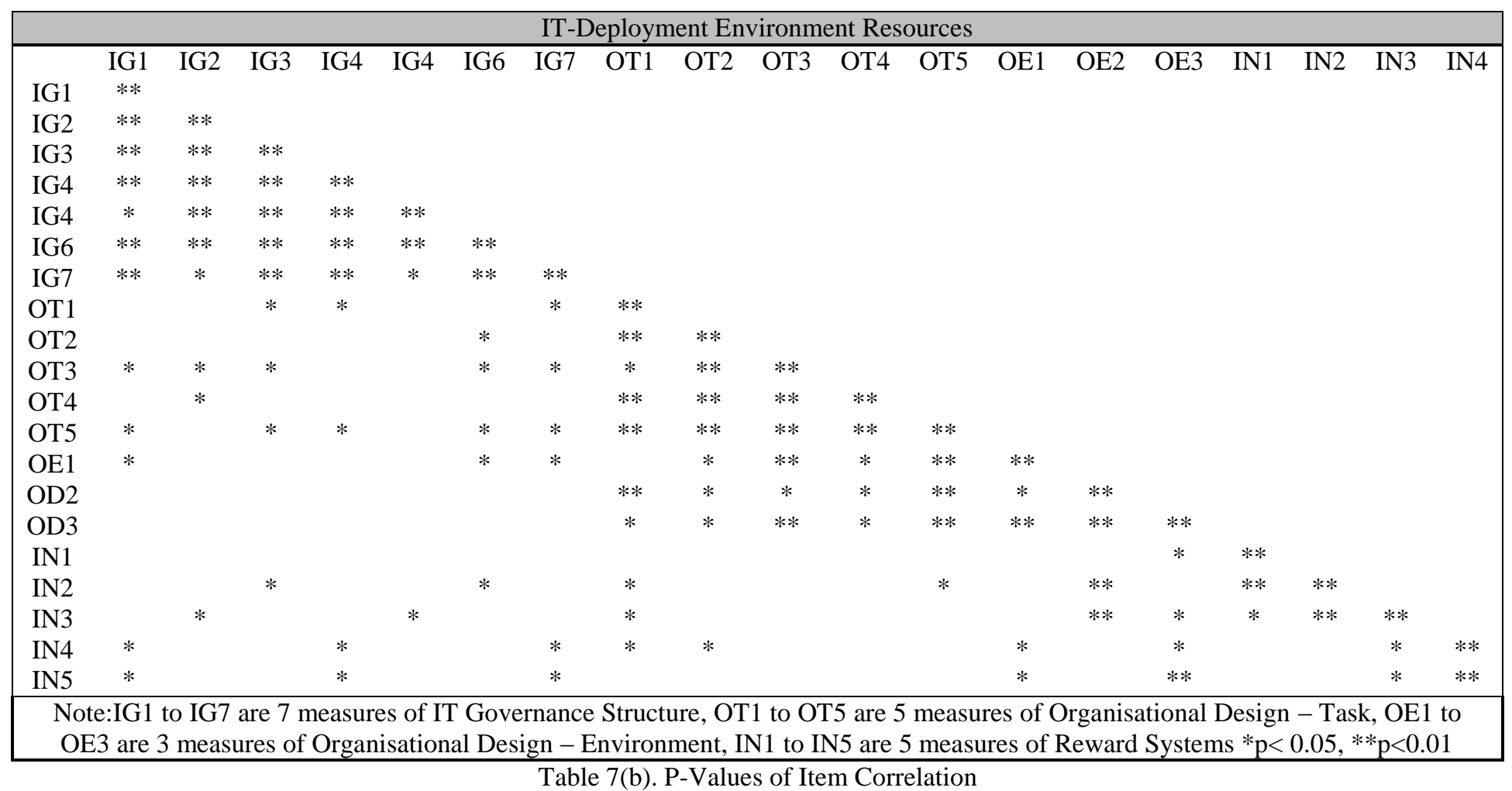


Cronbach's alpha greater than or equal to 0.70 suggests the items are uni-dimensional (Hair, Anderson, Tatham and Black, 2008). Reliability refers to the internal consistency of a measurement instrument (Hair et al., 2008). Cronbach's alpha is the common measure for internal consistency and should be higher than 0.80 (Hulland, 1999). The test of composite reliability (CR) determines the proportion of measure variance attributable to the underlying trait (Hulland, 1999). Reliable scales have CR that is greater than 0.50 (Hair et al., 2008; Hulland, 1999). The test of convergent validity measures that constructs that theoretically should be related to each other are, in fact, observed to be related to each other (Campbell and Fiske, 1959; Hair et al., 2008). Indicator factor loadings above 0.60 , construct composite reliabilities above 0.80 , average variance extracted (AVE) above 0.50 ensures convergent validity (Hulland, 1999).

Table 9 provides factor loadings and their significance measured using the t-values. The item loading in this confirmatory approach is largely above the strict rule of thumb of 0.70 (Nunnally, 1978). Table 10 provides the quality measures for the constructs. All constructs have Cronbach's alpha above 0.70 , and AVE above 0.50. The composite reliability for all constructs is above 0.80 . Comparison of the square root of AVE and inter-construct correlations showed that the square root of AVE for each construct was higher than their inter-construct correlations. Table 11 presents this comparison. The values in bold in Table 11 is the square root of AVE of the construct. This outcome ensured the discriminant validity of the field test data.

\begin{tabular}{|c|c|c|c|c|}
\hline Construct to Item & Loading & $\begin{array}{l}\text { Standard } \\
\text { Deviation }\end{array}$ & Standard Error & T-Stat \\
\hline ITG1 $\leftarrow$ ITG & 0.89 & 0.04 & 0.04 & 20.12 \\
\hline ITG2 $\leftarrow$ ITG & 0.71 & 0.10 & 0.10 & 7.47 \\
\hline ITG3 $\leftarrow$ ITG & 0.84 & 0.05 & 0.05 & 16.47 \\
\hline ITG4 $\leftarrow$ ITG & 0.89 & 0.05 & 0.05 & 16.93 \\
\hline ITG5 $\leftarrow$ ITG & 0.73 & 0.07 & 0.07 & 10.06 \\
\hline ITG6 $\leftarrow$ ITG & 0.91 & 0.04 & 0.04 & 24.23 \\
\hline ITG7 $\leftarrow$ ITG & 0.90 & 0.04 & 0.04 & 22.00 \\
\hline OTM1 $\leftarrow$ OTM & 0.75 & 0.26 & 0.26 & 3.72 \\
\hline OTM2 $\leftarrow$ OTM & 0.71 & 0.35 & 0.35 & 3.46 \\
\hline $\mathrm{OTM} 3 \leftarrow$ OTM & 0.72 & 0.35 & 0.35 & 3.05 \\
\hline OTM4 $\leftarrow$ OTM & 0.82 & 0.39 & 0.39 & 2.09 \\
\hline OTM5 $\leftarrow$ OTM & 0.71 & 0.29 & 0.29 & 2.60 \\
\hline OTW1 $\leftarrow$ OTW & 0.72 & 0.21 & 0.21 & 3.41 \\
\hline OTW2 $\leftarrow$ OTW & 0.77 & 0.24 & 0.24 & 3.16 \\
\hline OTW3 $\leftarrow$ OTW & 0.78 & 0.27 & 0.27 & 4.94 \\
\hline CRS1 $\leftarrow$ CRS & 0.72 & 0.13 & 0.13 & 4.68 \\
\hline $\mathrm{CRS} 2 \leftarrow \mathrm{CRS}$ & 0.73 & 0.15 & 0.15 & 4.72 \\
\hline $\mathrm{CRS} 3 \leftarrow \mathrm{CRS}$ & 0.78 & 0.07 & 0.07 & 11.13 \\
\hline CRS4 $\leftarrow$ CRS & 0.86 & 0.06 & 0.06 & 13.36 \\
\hline CRS5 $\leftarrow$ CRS & 0.83 & 0.08 & 0.08 & 10.99 \\
\hline
\end{tabular}

Table 9. Factor Loadings and Significance 


\begin{tabular}{|l|l|l|l|}
\hline Constructs & $\begin{array}{l}\text { Average } \\
\text { Variance } \\
\text { Extracted } \\
\text { (AVE) }\end{array}$ & $\begin{array}{l}\text { Composite } \\
\text { Reliability } \\
\text { (CR) }\end{array}$ & $\begin{array}{l}\text { Cronbach's } \\
\text { Alpha (CA) }\end{array}$ \\
\hline Lateral IT Governance Structure & 0.71 & 0.94 & 0.93 \\
\hline Organisation Design - Task Allocation & 0.58 & 0.87 & 0.80 \\
\hline Organisation Design-Teamwork Environment & 0.54 & 0.89 & 0.82 \\
\hline Congruent Reward Systems & 0.72 & 0.93 & 0.90 \\
\hline
\end{tabular}

Table 10. Quality Measures of Constructs

\begin{tabular}{|l|l|l|l|l|}
\hline \multicolumn{5}{|l|}{} \\
\hline & ITG & OTM & OEW & CRS \\
\hline Lateral IT Governance Structure & $\mathbf{0 . 8 4}$ & & & \\
\hline Organisational Design - Task Allocation & 0.46 & $\mathbf{0 . 7 6}$ & & \\
\hline $\begin{array}{l}\text { Organisational Design-Teamwork } \\
\text { Environment }\end{array}$ & 0.38 & 0.46 & $\mathbf{0 . 7 3}$ & \\
\hline Congruent Incentive Systems & 0.49 & 0.55 & 0.58 & $\mathbf{0 . 8 5}$ \\
\hline
\end{tabular}

Table 11. Square Root of AVE and Inter-Construct Correlations

\section{DISCUSSION}

Organisations need to consider continually ways to leverage their IT resources. IT resources play a significant role in enabling various transformations in organisations' business processes (Tallon, 2007; Tallon, 2010). That is, IT resources are seen as one of the key tools necessary to achieve competitive advantage. For these reasons, organisations continually adopt modern IT resources. However the strategic necessity hypothesis (Powell and Dent-Micallef, 1997) tells us that IT resources, per se, do not provide unique value to organisations. Rather, organisations' IT-related capabilities may uniquely leverage the IT resources, and this leveraging becomes a source of their competitive advantage. This situation means more attention is needed to research relating to identifying, developing, and sustaining organisations IT-related capabilities.

Organisations' initiatives of competence development needs to be unique (Grant, 2008; Teece, 2007) because competencies should be unique to organisations and they should not be easily imitated, substituted, or appropriated (Mata et al., 1995; Wade and Hulland, 2004). To achieve this situation, organisations need to develop unique environments on which to develop these IT-related competencies. While the elements of a unique environment may be known to other organisations, an organisation's ability to fit the elements together, and find a unique level of synergy between them would make their environment unique.

In this study, we describe an environment - a dynamic IT-deployment environment, which is a product of synergy between four common resources. These common resources relate to a decentralised organisational design relating to task allocation, a decentralised organisational design relating to promotion of teamwork, a congruent incentive system, and a lateral IT governance structure. We shared that these elements and resources have a level of synergy between each other, and understanding this synergy between the elements and resources results in the development of a dynamic IT-deployment environment. The essence of these environments is that they provide the necessary understanding and knowledge to the authorities, whose timing of decisions relating to the 
IT resources determine their IT-related capabilities. Recall, IT-related capabilities relate to the management understanding of the fit and value of IT to their organisations (Ray, Muhamma and Barney, 2005; Wade and Hulland, 2004), which also determine the nature of organisations' IT infrastructures (Broadbent and Weill, 1997; Melville et al., 2004; Ray et al., 2005). A dynamic ITdeployment environment is the necessary catalyst that embeds this understanding of the value of IT resources to organisations' decision-makers. We demonstrate how IT-related knowledge transfer is continually facilitated in this dynamic environment.

An important element in progressing empirical research relates to developing and validating measures for suggested constructs. This exercise provides researchers with the necessary tools to develop further understanding of issues by adopting and leveraging this new knowledge. We adopted a mature and robust set of procedures to develop reliable measures of the elements and resources of our suggested dynamic IT-deployment environment.

\section{RESEARCH CONTRIBUTIONS}

The theorising and development of a higher-level dynamic environment, and the measurement item development exercise outlined in this paper offers several contributions. First, this study reports a rigorous process of creating and validating measurement items for an organisational environment, the dynamic IT-deployment environment, with which organisations could develop new and sustain existing IT-related capabilities. This effort is important in understanding how organisations can continue to be competent with the use of their invested IT resources. The discussed procedures ensured high level of confidence in developing content validity, and establishing construct validity and reliability of the measurement items. The EFA and CFA showed that the suggested measurement items are reliable and purport to measure what they are supposed to measure. Future research could adopt this design to ensure strong reliability and validity in their empirical studies. This effort will be especially important in studies that may consider other forms of related resource interactions that result in other higher-level dynamic environments.

Second, future research could employ the measurement items developed in this study in various settings to investigate how organisations could be competent in developing new, and sustain their existing IT-related capabilities. Extant research (for example, Mata et al., 1995; Melville et al., 2004; Wade and Hulland, 2004) suggests various IT-related capabilities and marginal IT-related capabilities. Marginal IT-related capabilities possess some unique competences, but these competencies are not significant to provide competitive advantage. Organisations could differentiate themselves if they could transform marginal IT-related capabilities to new IT-related capabilities. Much of this competence development is best undertaken internally, as internally, organisations have the unrestrictive freedom to manage their own various resources (Coase, 1937). Organisations need to question their existing resource organisation, and understand how reorganisation of these resources could provide them with necessary competencies to improve their business processes. Middle management capability of shared organisational knowledge, and top management capability of top management commitment towards IT-related initiatives drive the adoption, and use, of IT resources in organisations (Ray et al., 2005). The suggested dynamic IT-deployment environment is an ideal vehicle to re-examine these IT-related capabilities to determine ways to renew or expand their commitment towards organisational IT requirements.

Research can also consider how the suggested dynamic IT-deployment environment develops a flexible IT infrastructure. This effort is important because a flexible IT infrastructure can recognise opportunities better, and embed them into organisations' information systems. Sustainable IT-related capabilities can also influence how firms invest in emerging communication and collaborative tools. 
Web 2.0 tools present enormous opportunities to businesses to improve their communication and collaboration. The extent of organisations penetration into these technologies will be contingent upon management knowledge of the benefit of these technologies. Research can examine how dynamic capabilities can develop this understanding, and help organisations in utilising these assets to improve their business value.

Third, this paper informs on the need for well-developed and validated measurement instruments in IS research. This effort is especially important as it contributes quantitative empirical credibility to IS research, and strengthens the IS field. This paper suggests some insights to those intending to conduct similar evaluations to strengthen their empirical investigations.

\section{LIMITATIONS}

This research has some limitations. First, we achieved a response rate of 10.75 percent on our pilot study. While this rate of response is considered appropriate (Jeffers et al., 2008), this could present some bias in the outcomes of the analysis of this data. However, we received 268 responses, which was adequate to conduct the required tests to determine the measurement properties of pilot test data. Second, despite rigorous attempts to validate the perceptive measures, and careful administration of the survey instrument, perceptions are susceptible to bias and error. But, we envisage our efforts have minimised these errors and biases.

\section{CONCLUSION}

The instrument development effort discussed in this paper attempts to improve organisations' competencies with the use of their IT resources. This effort will help addresses the important aspect of ways to develop new, and sustain organisations' IT-related capabilities. Further, this study sets the foundation to consider other combinations of resources that could create dynamic IT-deployment environments. Organisations could have other resources in their bundle of resources whose synergy could create other higher-level environments. The theoretical frameworks suggested in this study can help in suggesting these environments, and our discussed approach can help in developing and validating measurement items of the elements of such environments. Our effort contributes to moving this aspect of IS research forward. We envisage this research effort improves our understanding on how organisations could become smarter in the use of their IT resources.

\section{REFERENCES}

Baily, T. (1993) Discretionary Effort and the Organization of Work: Employee Participation and Work Reform since Hawthorne, New York: Institute on Education and the Economy, Teachers College, Columbia University.

Baker, G., Gibbons, R. and Murphy, K.J. (2002) Relational contracts and the theory of the firm, Quarterly Journal of Economics, 117, 39-85.

Barney, J.B. (1991) Firm Resources and Sustained Competitive Advantage, Journal of Management, $17,1,99-120$.

Barua, A., Kriebel, C.H. and Mukhopadhyay, T. (1995) Information Technologies and Business Value: An Analytic and Empirical Investigation, Information Systems Research, 6, 1, 3-23.

Barua, A., Lee, C.H. and Whinston, A.B. (1996) The Calculus of Reengineering, Information Systems Research, 7, 409-428. 
Becker, B.W. and Gerhart, B. (1996) The Impact of Human Resource Management of Organisational Performance: Progress and Prospects, Academy of Management Journal, 39, 4, 779-801.

Bowen, P.L., Chung, M.D. and Rohde, F.H. (2007) Enhancing IT Governance Practices: A model and Case Study of an Organisation's Efforts, International Journal of Accounting Information Systems, 8, 191-221.

Bresnahan, T., Brynjolfsson, E. and Hitt, L.M. (2002) Information Technology, Workplace Organization, and the Demand for Skilled Labor: Firm-Level Evidence, The Quarterly Journal of Economics, 117, 339-376.

Brickly, J.A., Smith, C.W. and Zimmerman, J.L. (1996) Organisational Architecture: A Managerial Economics Approach, Irvin, New York.

Broadbent, M. and Weill, P. (1997) Management by maxim: How business and IT managers can create IT infrastructures, Sloan Management Review, 38, 3, 77-92.

Brown, C.V. (1997) Examining the Emergence of Hybrid IS Governance Solutions: Evidence from a Single Case Site, Information Systems Research, 8, 1, 69-94.

Brynjolfsson, E. and Hitt, L. (1997) MIT analysis: Breaking boundaries, Informationweek, 649, 5461.

Brynjolfsson, E. and Hitt, L.M. (1998) Information Technology and Organisational Design: Evidence from Micro Data, Working Paper, MIT Sloan School of Management.1-47.

Campbell, D.T. and Fiske, D.W. (1959) Convergent and discriminant validation by the multitraitmultimethod matrix, Psychological Bulletin, 56, 2, 81-105.

Coase, R. (1937) The nature of the firm, Economica, 4, 386-405.

Cohen, J. (1960) A coefficient of agreement for nominal scales.37-46.

Davis, F.D. (1989) Perceived Usefulness, Perceved Ease of Use, and User Acceptance of Information Technology, MIS Quarterly, September, 319-340.

Doll, M.W. and Torkzadeh, G. (1987) The Relationship of MIS Steering Committee to Size of Firm and Formalisation of MIS Planning, Communication of the ACM, 30, 11, 972-978.

Earl, M.J. (1993) Experiences in strategic information systems planning, MIS Quarterly, 17, 1, 1-24.

Edgeworth, F.Y. (1881) Mathematical Physics, Kegan Paul, London.

Grant, R.M. (2008) Contemporary Strategy Analysis, Blackwell Publishing, Oxford.

Hair, J., Anderson, R., Tatham, R. and Black, W. (2008) Multivariate Data Analysis Prentice Hall.

Hayek, F.A.v. (1945) The use of knowledge in society, American Economic Review, 35, 519-530.

Hitt, L.M. and Brynjolfsson, E. (1997) Information Technology and Internal Firm Organization: An Exploratory Analysis, Journal of Management Information Systems, 14, 81-101.

Holmstrom, B. (1999) Managerial incentive problems: A dynamic perspective, Review of Economic Studies, 66, 169-182.

Hulland, J. (1999) Use of partial least squares (PLS) in strategic management research: a review of four recent studies, Strategic Management Journal, 20, 195-204.

Huselid, M.A. (1995) The Impact of Human Resource Management Practices on Turnover, Productivity, and Corporate Financial Performance Academy of Management Journal, 38, 3, 635-672.

Ichniowski, C., Shaw, K. and Prennushi, G. (1997) The Effects of Human Resource Management Practices on Productivity: A Study of Steel Finishing Lines, American Economic Review, 87, 291-315. 
IT Governance Institute (2007) IT Governance Status Report, www.itgi.org.

Jeffers, P.I., Muhamma, W.A. and Nault, B.R. (2008) Information Technology and Process Performance: An Empirical Investigation of the Interaction Between IT and Non-IT Resources, Decision Sciences, 39, 4, 703-735.

Jensen, M. and Meckling, W. (1992) Knowledge, Control and Organisational Structure, in L. Werin and H. Wijkander (Eds.) Contract Economics, Blackwell, Cambridge, 1992.

Johnson, A.M. and Lederer, A.L. (2005) The Effect of Communication Frequency and Channel Richness on the Convergence Between Chief Executive and Chief Information Officers, Journal of Management Information Systems, 22, 2, 227-252.

Kandel, E. and Lazear, E. (1992) Peer Pressure and Partnership, Journal of Political Economy, 100, 4, 801-817.

Karimi, J., Bhattacherjee, A., Gupta, Y.P. and Somers, T.M. (2000) The Effects of MIS Steering Committees on Information Technology Management Sophistication, Journal of Management Information Systems, 17, 2, 207-230.

Mata, F.J., Fuerst, W.L. and Barney, J.B. (1995) Information technology and sustained competitive advantage: A resource-based analysis, MIS Quarterly, 19, 4, 487-505.

Melville, N., Kraemer, K. and Gurbaxani, V. (2004) Information Technology and Organizational Performance: An Integrative Model of IT Business Value, MIS Quarterly, 28, 2, 283-321.

Milgrom, P. and Roberts, J. (1990) The economics of modern manufacturing: Technology, strategy, and organization, American Economic Review, 80, 511-528.

Milgrom, P., Roberts, J. and March, M. (1995) Complementarities and Fit: Strategy, Structure, and Organizational Change in Manufacturing, Journal of Accounting and Economics, 19, 179-208.

Moore, G.C. and Benbasat, I. (1991) Development of an Instrument to Measure the Perceptions of Adopting an Information Technology Innovation, Information Systems Research, 2, 192-222.

Nolan, R. (1982) Managing Information Systems by Committee, Harvard Business Review, 60, 4, 71 79.

Nolan, R. and Croson, D.C. (1995) Creative Destruction Havard Business School Press, Boston, MA.

Nunnally, J.C. (1978) Psychometric Theory, McGraw-Hill, New York, NY.

Oh, L.-B., Ng, B.L.-T. and Teo, H.-h. (2007), IT Portfolio Management: A Framework for Making Strategic IT Investment Decisions, in H. Österle, J. Schelp and R. Winter (Eds.) Proceedings of the Fifteenth European Conference on Information Systems, St. Gallen, University of St. Gallen, 1265-1275.

Osterman, P. (1994) How Common is Workplpace Transformation and Who Adopts it?, Industrial and Labour Relations Review, 47, 2, 173-188.

Pavlou, P.A. and El Sawy, O. (2006) From IT Leveraging Competence to Competitive Advantage in Turbulent Environments: The Case of New Product Development, Information Systems Research, 17, 3, 198-227.

Polanyi, M. (1962) Tacit knowledge: Its bearing on some problems of philosophy, Reviews of Modern Physics, 34.

Polanyi, M. (1966) The Tacit Dimension, Doubleday, New York.

Powell, T.C. and Dent-Micallef, A. (1997) Information Technology as Competitive Advantage: The Role of Human, Business, and Technology Resources, Strategic Management Journal, 18, 5, 375-405. 
Powell, T.C., Lovallo, D. and Caringal, C. (2006) Causal Ambiguity, Management Perception, and Firm Performance, Academy of Management Review, 31, 1, 175-196.

Prasad, A., Green, P. and Heales, J. (2012) On IT governance structures and their effectiveness in collaborative organizational structures, International Journal of Accounting Information Systems, 13, 3, 199-220.

Prasad, A., Heales, J. and Green, P. (2010) A capabilities-based approach to obtaining a deeper understanding of information technology governance effectiveness: Evidence from IT steering committees, International Journal of Accounting Information Systems, 11, 3, 214-232.

Ray, G., Muhamma, W.A. and Barney, J.B. (2005) Information Technology and the Performance of Customer Service Process: A Resource-Based Analysis, MIS Quarterly, 29, 4, 625-653.

Sambamurthy, V. and Zmud, R.W. (1999) Arrangements for information technology governance: a theory of multiple contingencies, MIS Quarterly, 23, 261-290.

Silver, M.S. (1988) User Perceptions of Decision Support System Restrictiveness: An Experiment, Journal of Management Information Systems, 5, 1, 51-65.

Straub, D. (1989) Validating Instruments In MIS Research, MIS Quarterly, 13, 2, 147.

Straub, D., Boudreau, M.-C. and Gefen, D. (2004) Validation Guidelines for IS Positivist Research, The Communications of the Association for Information Systems, 13, 1.

Straub, D.W., Rai, A. and Klein, R. (2004) Measuring Firm Performance at the Network Level: A Nomology of the Business Impact of Digital Supply Networks, Journal of Management Information Systems, 21, 1, 83-114.

Tallon, P.P. (2007) A Process-Oriented Perspective on the Alignment of Information Technology and Business Strategy, Journal of Management Information Systems, 24, 3, 227-268.

Tallon, P.P. (2010) A Service Science Perspective on Strategic Choice, IT, and Performance in U.S. Banking, Journal of Management Information Systems, 26, 4, 219-252.

Teece, D. (2007) Explicating Dynamic Capabilities: The Nature and Microfoundations of (Sustainable) Enterprise Performance, Strategic Management Journal, 28, 1319-1350.

Teece, D.J., Pisano, G. and Shuen, A. (1997) Dynamic capabilities and strategic management, Strategic Management Journal, 18, 509-533.

Van Grembergen, W., De Haes, S. and Guldentops, E. (2004) Structures, Processes, and Relational Mechanisms for IT Governance, in W. Van Grembergen (Ed.) Strategies for Information Technology Governance, Idea Group Publishing, Hershey, PA, 2004, 1-36.

Wade, M. and Hulland, J. (2004) Review: The resource-based view and information systems research: Review, extension, and suggestions for future research, MIS Quarterly, 28, 1, 107-142.

Weill, P. and Ross, J.W. (2004) IT Governance: How Top Performers Manage IT Decision Rights for Superior Results, Harvard Business School Press, Boston, MA.

Wright, P.M. and McMahan, G.C. (1992) Theoretical Perspectives for Strategic Human Resource Management, Journal of Management, 18, 2, 295-320.

Xue, Y., Liang, H. and Boulton, W.R. (2008) Information Technology Governance in Information Technology Investment Decision Processes: The Impact of Investment Characteristics, External Environment, and Internal Context, MIS Quarterly, 32, 1, 67-96. 